\title{
MISTRAL MISTRAL
}

Journal of Latin American Women's

Intellectual \& Cultural History

\section{Redefiniciones: Los Otros góticos}

\author{
Marta Sierra, Kenyon College, US
}

To cite this article: Marta Sierra. 2021. "Redefiniciones: Los Otros góticos." Mistral: Journal of Latin American Women's Intellectual \& Cultural History 1 (1): 119-131, https://doi.org/10.21827/mistral.1.37518

\begin{abstract}
This article addresses a redefinition of the Gothic genre as a "Red Gothic," a term that I coin to define the visceral traits of literary and artistic productions of the "horror" genre in Latin America. I center on the works of Mariana Enríquez, placing them in dialogue with those of visual artists Ana Mendieta and Teresa Margolles. This is an initial proposal for further discussion on political uses of the Gothic in Latin America. In response to the violence and discrimination produced by different implementations of Neoliberalism in the region, a growing field of artists and writers work with Gothic imagery in a flexible, hybrid way to create new representations of "monsters" and "cannibals." By looking at feminist critiques on posthumanism and cyborg identities (Rosi Braidotti, Donna Haraway), I propose that "Red Gothic" embodies those gaps and erasures of different populations that still claim a place in Latin American societies.
\end{abstract}

\section{Keywords}

Gothic fiction; Gothic art; cyborgs; post-humanism; monsters; cannibals; Mariana Enríquez.

\section{Resumen}

Este artículo redefine el género Gótico como un "Rojo Gótico," un término que refiere a la visceralidad de algunas producciones culturales contemporáneas en América Latina. Me concentro en la ficción de Mariana Enríquez en diálogo con estéticas de la desaparición y la muerte en el arte de Ana Mendieta y Teresa Margolles. Es mi intención proponer aquí una discusión más amplia sobre los usos políticos del Gótico. Considero que un importante grupo de escritores y artistas en América Latina usan las imágenes y la retórica del Gótico para representar a los nuevos "monstruos" quienes sufren los efectos de la pobreza, la discriminación y la violencia. Las teorías de lo post-humano y de la subjetividad ciborg (Rosi Braidotti y Donna Haraway) sirven como un marco teórico para pensar en las reconstrucciones y traducciones del género.

\section{Palabras claves}

Ficción Gótica; arte Gótico; ciborgs; post-humanismo; monstruos; caníbales; Mariana Enríquez. 


\title{
Redefiniciones: Los Otros góticos
}

\author{
Marta Sierra, Kenyon College, US
}

\begin{abstract}
"El gótico importa" se titula el número especial de la publicación Text Matters. A Journal of Literature, Theory and Culture $(2016,6)$. Aunque el gótico se asocie en sus orígenes con argumentos, personajes y temas alejados de la realidad cotidiana, la crítica nota la importancia del género en el tratamiento de la violencia y el miedo de contactos culturales generados por la globalización y el neoliberalismo. El gótico da voz a nuevos monstruos, zombis o fantasmas, cuerpos no-normativos de nuestra modernidad contemporánea: "The most interesting cultural work of the Gothic is linked to its creative explorations of the nonnormative aspects of life, such as the body in its queer, raced, gendered and physical materiality" (Soltysik Monnet, 2016, 8). Las ficciones y trabajos artísticos que analizo aquí demuestran la vitalidad de este horror a "lo otro". El orden neoliberal y sus violencias múltiples nos lleva aquí a ver como los monstruos representan el deseo y la ansiedad de un nuevo orden de subjetividades y derechos. Es numerosa la crítica que ha estudiado lo gótico en América Latina. ${ }^{1}$ Pero no hay un enfoque en la relación entre gótico y los reclamos de género contemporáneos, en particular en lo que concierne a la trata de personas, la violencia de género y el feminicidio. En la producción cultural latinoamericana podemos rastrear una tradición que hizo de lo femenino monstruoso y del "otro genérico" monstruoso un instrumento de experimentación estética y una forma de reclamo social. Son numerosos los estudios sobre la heterogeneridad feminista del surrealismo y la vanguardia (María Luisa Bombal, Norah Lange, Silvina Ocampo y más tarde Alejandra Pizarnik). Y también la crítica que traza la relación de la violencia dictatorial y la creación de anomalías de los "otros cuerpos" como en Griselda Gambaro, Luisa Valenzuela y Diamela Eltit.

¿Pero qué ocurre con el género Gótico y su dimensión de género sexual? Frente al feminicidio, la trata de personas, los asesinatos en masa y la violencia concitada por la guerra de las drogas, la escritura de América Latina está dando forma a nuevos mecanismos para narrar el horror, en la creación de un "gótico" que se centra en la violencia sobre el cuerpo. El miedo lo causan aquí no castillos o fantasmas abandonados, sino la coexistencia diaria con la discriminación y la violencia, la permanente situación de riesgo que se viven
\end{abstract}

\footnotetext{
${ }^{1}$ Hay excelentes ejemplos de exploraciones sobre el gótico latinoamericano entre las que se encuentran volúmenes como, Ecos góticos en la novela del Cono Sur de Nadina Estefanía Olmedo (2013); Selva de fantasmas. El gótico en la literatura y el cine latinoamericanos (2017) y The Migration and Politics of Monsters in Latin American Cinema (2018) ambos títulos de Gabriel Eljaiek-Rodríguez; Latin American Gothic in Literature and Culture (2018) de Sandra Casanova-Vizcaíno y Inés Ordiz (2018) y, de Rosana Díaz- Zambrana y Patricia Tomé, Horrofílmico: Aproximaciones al cine de terror en Latinoamérica y el Caribe (2012). Como señalan acertadamente Sandra Casanova-Vizcaíno e Inés Ordiz el gótico ha sido considerado a veces como una imposición cultural de las literaturas del llamado centro europeo y norteamericano $(2018,36)$. Pero coincido con estas autoras en que más que un género, el gótico es un modo de escritura que, como la historia literaria de América Latina demuestra, ha estado unido a distintas manifestaciones de la producción cultural. Es evidente que muchos de los temas sobre la violencia neoliberal se entroncan con otras violencias históricas sobre los cuerpos que adquieren representación en la mirada gótica: la colonización, la militarización, la esclavitud, el prejuicio de clase social, raza y género, la violencia de tortura y desaparición de personas.
} 
en muchas sociedades latinoamericanas. El romanticismo europeo forjó un género que experimentaba con el horror como una experiencia extrema alejada de la sociedad. El gótico se funda como un género que, obsesionado con la guerra, busca lidiar con el trauma de la violencia alejándolo del lector. ${ }^{2}$ Lo gótico se considera en sus orígenes europeos como el pasado bárbaro de la Edad Media y no es curioso que en la literatura actual se reedite como una escritura donde el miedo del otro, el miedo del "bárbaro", el miedo a la invasión sean los tropos centrales. El cuerpo del otro, en este gótico de la violencia, es lo que se aborrece y se teme. ${ }^{3}$ Dos son las figuras centrales dentro de esta tradición que merecen un enfoque crítico en relación con nuestra contemporaneidad: el monstruo y el caníbal.

El monstruo gótico en su versión más popularmente conocida es el que, innombrado, aparece en Frankenstein. Mary Shelley escribió Frankenstein, or, the Modern Phometheus durante unas vacaciones de verano en Suiza. Lord Byron, Percy Bysshe Shelley (su futuro marido) y el médico John Polidori hacen una apuesta sobre quién podía escribir el mejor relato de horror. La novela de Mary Shelley se publicó en 1818, mientras que el relato "The Vampyre," de Polidori se cree que influyó en el Drácula de Bram Stoker (Hall, 2018). La figura del híbrido, como en el caso de Frankenstein, cuestiona el orden de lo humano y las posibilidades de variación corporal. La aproximación biográfica a la obra de Shelley señala que su novela es una invectiva contra la masculinidad romántica y su egoísmo e idealismo que no se preocupa por otros. Otros estudiosos han señalado que el tema del género, en especial de la maternidad, es central en la formación del monstruo. Como señala Suparna Banerjee, el científico ha sido comparado con la madre dando nacimiento a su hijo y en esto, es una advertencia sobre los excesos de la ciencia y su ideología reductiva y sexista que reitera el dualismo entre "naturaleza" y "cultura" con todas las implicaciones sociales que esta división tiene (Barnejee, 2014, 12). La influencia de la madre de Shelley, Mary Wollstonecraft, y su crítica sobre los derechos de la mujer es evidente en Frankeinstein. Como señalo en la siguiente sección, los conceptos feministas de lo "post-humano" (Rosi Braidotti, 2015) y el ciborg (Donna Haraway) son centrales para examinar el resurgimiento de monstruos y caníbales en la literatura contemporánea. Propongo aquí que la crítica de género que aparece en estas ficciones tiene que ver con la formación de una nueva corporalidad y de la formación de identidades no-normativas.

Como exhiben las numerosas referencias culturales contemporáneas a los zombies (transformados en caníbales a partir del cine de George Romero), el deseo de devorar al otro y el terror de la invasión son centrales en las narrativas de miedo que vemos en distintos medios. De este modo, lo monstruoso sirve para analizar la violencia y la

\footnotetext{
${ }^{2}$ La crítica ha señalado el surgimiento del gótico en relación a la llamada "Guerra de los Siete Años" en que se confronta el colonialismo europeo tanto en países de Africa, América y Asia. Como señala Fred Botting, el término "gótico" proviene del género arquitectural de la Edad Media y que se asocia con un resurgimiento del nacionalismo: "The dominance of classical values produced a national past that was distinct from the cultivation, rationality and maturity of an enlightened age. This past was called Gothic, a general and derogatory term for the Middle Ages which conjured up ideas of barbarous customs and practices, of superstition, ignorance, extravagant fancies and natural wildness" (Botting, 2005,15).

${ }^{3}$ Mary Mulvey-Roberts denomina así el "gótico corporal": "As a body of writing, the Gothic has its own inherent dangers. Not only does it unlock taboos and collapse boundaries, but it can also generate and perpetuate negative stereotypes by stigmatizing the inassimilable Other as dangerous body" (Mulvey Roberts, 2016, 2). Gabriel Eljaiek-Rodríguez explica como en el caso latinoamericano este miedo hacia el otro y su corporalidad se origina en los monstruos de la conquista, en la escritura de Columbus y de los cronistas, en la imagen original de los Caribes como seres deficientes y malformados (Eljaiek-Rodríguez 2018).
} 
destrucción en América Latina. Son ahora los monstruos caníbales que emergen en las ficciones, por ejemplo, de Mariana Enríquez. El caníbal ha sido una figura central en la historia del colonialismo en América Latina. Desde el uso de un canibalismo en reversa en el Movimiento de Antropofagia en Brasil hasta el Calibán de Roberto Fernández Retamar en Cuba, el caníbal ha sido empleado como una forma de negociar los contactos culturales y buscar formas de dar respuesta a la violencia producida por el colonialismo. En el cuento "El patio del vecino", Mariana Enríquez vuelve a esta figura para tratar el tema de la discriminación y la violencia en Argentina. La crítica ha señalado la recurrencia de los niños monstruos en la obra de Enríquez. ${ }^{4}$ Cuentos de esta colección como "Bajo el agua negra" y "El chico sucio" muestran en la figura monstruosa del niño o del adolescente como la violencia afecta a los más vulnerables. Estos tres cuentos de la colección tienen lugar en Buenos Aires, en barrios alejados del centro como La Boca o Constitución, y plantean las tensiones en la ciudad y en un país transitando por políticas de exclusión y pobreza. Una segunda preocupación en la obra de Enríquez es la violencia de género. En "Las cosas que perdimos en el fuego" Enríquez responde directamente al feminicidio y a la quema de mujeres por fuego o ácido, un hecho cada vez más frecuente no sólo en Argentina sino también en otros países. En el cuento "Carne" la autora nos presenta con el canibalismo como una respuesta a los medios de comunicación y la violencia de género que emana de ellos. Este cuento en consonancia con la novela breve de Gabriela Cabezón Cámara, Beya. Le viste la cara a Dios (2013), la relación entre canibalismo y género lleva al lector a la tradición de El Matadero (1871) de Esteban Echeverría. El consumo de carne unido a la violencia simbólica tal como lo presenta Echeverría, se emplea en esta novela para pensar en el consumo de la mujer en prácticas como la trata de personas y la prostitución. En otro contexto, pero con imágenes compatibles a estas ficciones, la obra de Teresa Margolles refiere a la violencia del narcotráfico con las figuras metonímicas de la sangre, la ropa y otras formas de "dejos de violencia" como los impactos de bala en un muro reconstruido luego de una lucha de clanes.

El monstruo, el caníbal, la sangre, la carne, son todas imágenes que producen la internalización del "terror" en lo que Fred Botting denomina la "ambivalencia emocional del Gótico": mientras que el terror nos permite separar lo que nos provoca miedo de lo que el lector o el espectador considera "la norma" (la distancia, por ejemplo, del castillo, del monstruo), el horror disuelve la ilusión de la separación, de la reconstitución de una seguridad del yo. El horror nos muestra que los monstruos están más cerca de lo que pensamos, que las distancias y las fronteras no van a contenerlos (Botting, 2005, 6). Los monstruos, aunque no queramos verlos, están tocando a nuestra puerta.

\section{Las cosas que perdimos en el fuego: El ciborg y la radicalidad de la diferencia}

En los años ochenta Donna Haraway redefinió la agencia feminista a partir del impacto de la tecnología y el surgimiento de otras prácticas feministas, como las del feminismo de color. Formada como científica, Haraway plantea la necesidad de un conocimiento situado: la práctica feminista ha fallado (como el liberalismo humanista) en responder a las

\footnotetext{
4 Ver al respecto Ana Gabriela Angulo, "La ciudad monstruo(sa) en cuentos de Mariana Enríquez," Jornaler@s. Revista científica de estudios literarios y lingüísticos. 3.3 (2017): 309-318.
} 
necesidades diversas de género y reivindicación social. Haraway está en contra del esencialismo y las políticas de identidad. Pensando en expandir la noción de identidad e imbuida sobre el debate entre ciencia y naturaleza en relación al control reproductivo muy popular en los años ochenta, Haraway propone el "ciborg" como una forma potente de reconfigurar el feminismo: "I am making an argument for the cyborg as a fiction mapping our social and bodily reality and as an imaginative resource suggesting some very fruitful couplings... The cyborg is our ontology; it gives us our politics. The cyborg is a condensed image of both imagination and material reality, the two joined centers structuring any possibility of historical transformation" (Haraway, 2004,8).

Cercano a la figura del monstruo o del zombi, el ciborg como ser híbrido nos permite cuestionar el concepto de lo humano y, como en Frankenstein, las relaciones entre naturaleza y cultura. El monstruo en la literatura gótica apunta además a una crítica al eurocentrismo y occidentalismo. En un momento en que pandemias como el COVID 19 nos llevan a preguntarnos sobre el futuro del modelo extractivista y destrucción medioambiental, un modelo de exclusión, disparidad económica, racial y étnica, de violencia de género, es por demás relevante pensar en cuál es el futuro de esta categoría de lo humano. No lejos de ciertos planteamientos de Haraway, Rosi Braidotti ha propuesto el "post-humanismo crítico", una subjetividad "vitalista, encarnada e integrada" y comprometida con su circunstancia (Braidotti, 2015, 57). Entender cómo funcionan los resortes de esta política post-humanista en América Latina es central para pensar en una imaginación literaria y artística que dé alternativas. El gótico invita esta reflexión.

El feminicidio es uno de los problemas más urgentes en América. Crónicas como la de Huesos en el desierto (2005) de Sergio Gonzáles Rodríguez señalan la espectacularidad de estos crímenes. Los cuerpos se dejan expuestos, a veces sólo partes de ellos, fragmentos de un pantalón, un zapato, una trabita del pelo. En otros casos, el asesino escoge la quema por fuego o por ácido. Deja que la víctima sufra unos minutos y luego extingue el cuerpo ardiendo. Solo unos minutos: tiempo suficiente para marcar la piel. El feminicidio muestra la violencia de consumir y destruir, de reclamar un cuerpo y hacerlo perecer. En algunos casos, como estudia la antropóloga Rita Segato, el feminicidio implica una dominación territorial unida al cuerpo, un diálogo entre hombres violentos compitiendo por una misma presa $(2010,75)$. En su estudio sobre los hombres encarcelados por actos de violación, Segato explica que el que viola establece un doble diálogo: por un lado, el violador le habla a la víctima y le reitera su dominación. Al contrario de esa enunciación vertical existe otra, horizontal, dirigida a los pares para establecer una identidad en un grupo:

El énfasis de mi análisis en este trabajo, a partir de una amplia escucha de los testimonios recogidos en la cárcel, apunta a un violador a quien, aun cuando actúa solo, podríamos describir como "acompañado" por su conciencia como un paisaje mental "con otras presencias", y a un acto íntimamente ligado al mandato de interlocutores presentes en el horizonte mental, el ámbito discursivo en que se realiza. Por consiguiente, mi modelo presupone una estructura dialógica, en el

\footnotetext{
${ }^{5}$ Como dice Braidotti, "mi sensibilidad posthumana podrá parecer visionaria y hasta impaciente, pero es, de verdad, propositiva, o para usar mi término preferido, es afirmativa. Una política afirmativa combina crítica y creatividad en la búsqueda de imágenes y proyectos alternativos" (58).
} 
sentido bajtiniano, entre el violador y otros genéricos, pobladores del imaginario, en la cual encuentra su sentido la violación, entendida como un acto expresivo revelador de significados.

La lectura de Segato es iluminadora porque nos muestra el modo en que este tipo de violencia de género es una enunciación, una puesta en escena. De hecho, la penalización creciente del feminicidio contempla su carácter público: "Los crímenes contra las mujeres tienen hoy una visibilidad que ni por asomo se apreciaba hace apenas unas décadas. Los homicidios 'pasionales' del pasado deben ser interpretados hoy día como crímenes que remiten al sentimiento patriarcal de patrimonialidad del cuerpo femenino" (Dora Barrancos, 2020).

La colección de cuentos Las cosas que perdimos en el fuego (2016) de Mariana Enríquez inserta el tema del feminicidio en este diálogo. Admiradora de Silvina Ocampo, Enríquez retoma el género mixturado de lo fantástico y lo gótico. Enríquez emplea en sus relatos una mirada y una voz sagaz. Narrados en tercera persona la mayoría de sus cuentos establece un desdoblamiento que permite el efecto del horror y la crítica social. En "El chico sucio", se muestra la situación paradójica de una protagonista obsesionada con rescatar a un chico que vive en la calle con su mamá drogadicta. En "Bajo el agua negra", es la fiscal que va a buscar en una villa a la orilla del Riachuelo a uno de los chicos desaparecidos por la violencia de la policía. Las apariencias, la confusión visual, el desconocimiento de lo que va a pasar son elementos clásicos del género. Enríquez los emplea estratégicamente para mostrar la vulnerabilidad de una visión estrecha de la realidad.

En el cuento que da el título a la colección, un grupo de mujeres se organiza contra la quema de mujeres, una forma de feminicidio común en países como Argentina. "Mujeres Ardientes" convoca a activistas que se quemen el cuerpo delante de una cámara, mientras la protagonista, Silvia las filma, y su madre asiste a las víctimas con los primeros auxilios y el traslado a los servicios médicos. Se trata de una quema que no es total, sino que sólo parcialmente desfigura a la activista-víctima. Como una protesta contra la desaparición y la muerte del feminicidio, estas mujeres quieren esgrimir las cicatrices como marcas de su negativa a ser víctimas. "Las quemas las hacen los hombres, chiquita. Siempre nos quemaron. Ahora vamos a quemarnos nosotras. Pero no nos vamos a morir: vamos a mostrar nuestras cicatrices" (Enríquez, 2016, 192). Las "Mujeres Ardientes" transformadas así en monstruos que caminan por la ciudad de Buenos Aires semejan los monstruos del gótico. En este caso, no se esconden en un ático o en una cueva. La primera víctima no sólo viaja por el tren subterráneo, sino que también cuenta su historia mientras se acerca a que le den un beso. El espectador, el lector se confrontan con la sensación de asco y rechazo físico que provoca este feminismo por violencia:

Su método era audaz: subía al vagón y saludaba a los pasajeros con un beso si no eran muchos; si la mayoría viajaba sentada. Algunos apartaban la cara con disgusto, hasta con un grito ahogado; algunos aceptaban el beso sintiéndose bien consigo mismos; algunos apenas dejaban que el asco les erizara la piel de los brazos, y si ella lo notaba, 
en verano, cuando podía verle la piel al aire, acariciaba con los dedos mugrientos los pelitos asustados y sonreía con su boca que era un tajo.

(Enríquez, 2016, 185-186)

La distorsión y la construcción de esta monstruosidad por el fuego es una estrategia que permite "visualizar" la violencia en el cuerpo. Aunque las quemas ocurran en su mayor parte en lugares privados o íntimos, los efectos son públicos y los motivos van más allá de una simple desavenencia en la pareja. El debate sobre la legalización del feminicidio como un crimen que va más allá del ámbito privado es uno de los temas centrales en la discusión de la pena que un feminicida debe pagar. Además de la transgresión de esta frontera entre lo privado y lo público, "Las cosas que perdimos en el fuego" dirige su crítica al modo en que la belleza puede ser, como la femineidad, una forma de destrucción de la agencia y la individualidad de una persona. La fealdad del cuerpo lacerado hace público el trauma.

El arte también ha empleado esta forma de denuncia, plasmando los efectos del trauma en distintos tipos de cicatrices. Ana Mendieta acude en sus primeras performances a imágenes de la sangre o la deformación física sobre la mujer como formas de criticar la cosificación del género. Uno de los ejemplos es la Muerte de la gallina (Death of a Chicken, 1972) y Sudando sangre (1973). En la primera performance, la artista sostiene una gallina recién sacrificada y luego usa la sangre que cae de su cuerpo como una pintura fresca. La performance termina con la artista cubriéndose de plumas blancas como si fuera ella misma una reencarnación de la gallina. De acuerdo con la tradición yoruba que sigue Mendieta en este ejemplo, la gallina representa en su blancura la virginidad de la muchacha para quien se ofrece el sacrificio y la sangre es una metáfora de la iniciación sexual. La crítica ha interpretado la sangre y las plumas como una forma de transformarse en la parte abyecta, intersticial entre mujer y animal que la sociedad patriarcal busca controlar. Como señala Escoda Agusti, "Through body art, [figures such as] Mendieta deterritorialize their own bodies, detaching them from social, mediated, ideological processes of subjection, exoring hybrid junctures (between pleasure ad pain, life and death, happiness and suffering) which in our society are mutually exclusive, their zones of ambiguity considered taboo" (Escoda Agusti, 2007, 310).

El tema de la violencia de género también aparece en la novela Le viste la cara a Dios. La bella durmiente (2011) de Gabriela Cabezón Cámara. Esta novela breve forma parte de un proyecto editorial que pidió en 2010 a varios escritores que hicieran la transcripción o reescritura de un cuento clásico y para ello, Cabezón Cámara escogió La Bella Durmiente. Beya, la protagonista, es una joven víctima de las redes de prostitución en el conurbano bonaerense que, después del secuestro, está obligada a prostituirse y vivir en el cautiverio de un burdel de Lanús. El título de "bella durmiente" juega con la ironía de como la violencia y la prostitución a la que es sometida la protagonista, va de la mano de la internalización de la subyugación y la docilidad. Este texto hace referencia directa a El Matadero de Echeverría, una influencia que la autora ha señalado como central en su escritura: "Si a Matasiete el matambre, a vos el resbalar de tu sangre" (Cabezón Cámara, 2011,6). La comparación de la trata con una carnicería llega al punto que las distintas partes del cuerpo de Beya se nombran como si fueran cortes de carne. Es claro el interés 
por la biopolítica como señala Nora Domínguez, (Cabezón Cámara y Domínguez, 2014, 23). ${ }^{6}$

Dentro del género gótico, los monstruos son formas de deshumanizar y volver abyecto a ese "otro" que parece amenazar el orden social. Sin embargo, en los tres ejemplos citados, las protagonistas hacen de la monstruosidad una forma de protesta. Como dice Ana Casas, el monstruo atenta contra el orden físico y cognitivo y contra el orden moral de la sociedad: "En este sentido, el monstruo posee una dimensión terrorífica, ya que encarna de forma simbólica los miedos más íntimos y antiguos del ser humano: es, en suma, la representación figurativa de nuestros propios temores" (Casas, 2012, 8). En la última sección me enfoco en la imagen del caníbal, otro equivalente a la figura de lo monstruoso.

\section{El caníbal: el yo y el otro}

En esta sección me concentro en dos definiciones del caníbal que sirven para el análisis de las geografías de miedo que reconstruyen ficciones como las de Mariana Enríquez. En primer lugar, la crítica señala que la figura del caníbal constituye y distingue identidades, una acepción que desde el momento de la llegada de los europeos a América ha implicado colonialismo y dominación cultural. El movimiento de antropofagia dentro del Modernismo brasilero asocia el canibalismo con una forma de consumo e intercambio cultural. En estas dos acepciones en los estudios del canibalismo cultural, la retórica del miedo y la disputa por el poder son centrales. ${ }^{7}$ Como mito en una construcción de otro y en trazar límites y políticas de identidad, el canibalismo "produce una diferencia": es un "espejo de diferencias, una mirada al otro que lo fija y que también reconoce y afirma este otro" (Jáuregui, 2005, 31).

Carlos Jáuregui explica el canibalismo como una forma de disputa de poder social entre los "desechables" que no consumen y la "burguesía" que encarna una ciudadanía del consumo. Los personajes de Mariana Enríquez cruzan las fronteras urbanas imaginarias o reales e ingresan en espacios que alimentan la imaginación del miedo. Los cuentos de la colección Las cosas que perdimos en el fuego abandonan el realismo social para insertar lo fantástico teñido de lo gótico en una discusión sobre la pobreza, la discriminación, la violencia social, la delincuencia y la prostitución infantil. Los cruces de fronteras llevan a los personajes a espacios lejanos del centro, los márgenes como La Boca o Constitución. La perspectiva del relato permite ver críticamente el modo en que los personajes, quienes son miembros de la burguesía, establecen una relación con el "otro" que vive en los márgenes. Astutamente, la narración de Enríquez confronta al lector junto al protagonista

\footnotetext{
${ }^{6}$ Shelley Jackson hace una reescritura de Frankenstein. Así como en el caso de Beya, el cuerpo femenino se fragmenta en secciones de "carne" para ser consumidas, Patchwork Girl (1995), lleva la imagen del monstruo femenino a una selección de partes del cuerpo que tienen voz y que narran su propia historia. La reducción de la mujer a una parte de su cuerpo - en la pornografía por ejemplo los órganos genitales - implica la reducción de la individualidad y el anulamiento de la dignidad como persona.

${ }^{7}$ Los estudios sobre el canibalismo cultural son numerosos. Me gustaría destacar aquí, Carlos Jáuregui. Canibalia. Canibalismo, calibalismo, antropofagia cultural y consumo en América Latina. Cuba: Casa de las Américas, 2005. Kilgour, Maggie. From Communion to Cannibalism: An Anatomy of Metaphors of Incorporation, Princeton, Princeton UP: 1990; Deborah Root, Cannibal Culture: Art, Appropriation and the Commodification of Difference. London, New York: Routledge, 1996; Mannoni, Octave. Prospero and Caliban; The Psychology of Colonization. New York, Praege, 1993.
} 
con los límites del prejuicio que en estos relatos conlleva la trampa del no saber o no poder ver que lleva al protagonista a la situación límite del desenlace. Es aquí donde la definición del caníbal es instrumental para entender estos encuentros interurbanos: la construcción de identidades es el "espejo de las diferencias" del que habla Jáuregui $(2005,34)$. Desde el centro, la burguesía ve sólo lo que quiere ver y recurre a la limosna del asistencialismo o del rescate para lidiar con la culpa de clase. No es casual que muchos de estos relatos tengan como protagonistas a mujeres de clase media que parecen tener una "conciencia social" y quienes se enfrentan con niños o adolescentes cuyos cuerpos llevan las marcas de la violencia y el hambre.

En la colección Las cosas que perdimos en el fuego hay muchos relatos que siguen este esquema, pero son centrales en la dinámica de clase "El chico sucio", "El patio del vecino" y "Bajo el agua negra". Aquí me concentro sólo en "El patio del vecino", cuya protagonista es una asistente social que ha perdido su trabajo en un hogar para niños en situación de riesgo. Paula y Miguel se mudan a un nuevo departamento que eligen sobre todo por la luminosidad para que Paula se recupere de su inestabilidad emocional. Frente a un Miguel que se afianza en este espacio para comenzar una nueva vida, Paula se aísla en un mundo de alucinación y miedo: "Los golpes que la despertaron eran tan fuerte que la hicieron dudar: debía ser una pesadilla. Hacían vibrar la casa. Los golpes en la puerta sonaban como puñetazos de unas manos enormes, manos de bestia, puños de gigante (...) En la oscuridad los golpes sonaban como algo a punto de entrar, a punto de derribar la puerta" (Enríquez, 2016, cursivas mías 133). Finalmente, un día ve a un niño sentado al borde de su cama mientras duerme, y unos días después, desde su terraza, un pie con una cadena atada al tobillo. Convencida de que se trata de un caso de abuso infantil, Paula decide entrar a la casa del vecino al día siguiente: "No veía bien, pero no hacía falta: las alacenas estaban llenas de carne podrida sobre la que crecían y se solazaban los gusanos blancos de la descomposición. Lo peor era que no podía distinguir qué carne era: si carne vacuna común que por insania el hombre había dejado pudrir ahí o alguna otra cosa" (Enríquez, 2016,149).

La falta de visión es un elemento central en la creación del horror en este cuento. Miguel la ha dejado y en su soledad con su gata, Paula vive sólo para la obsesión del chico que ha visto en el patio del vecino. No sabemos en realidad si el canibalismo es real o no. No sabemos quién es el caníbal, aunque al final el cuento nos deja con la imagen del chico vuelto monstruo cuando se come a la gata de Paula: "Era el chico del patio del vecino. Tenía marcas de la cadena en el tobillo, que en unas partes sangraba y en otras supuraba infección. Cuando escuchó su voz, el chico sonrió y ella le vio los dientes. Se los habían limado y tenían forma triangular, eran como puntas de flecha, como un serrucho" (Enríquez, 2016,152).

El niño monstruo confronta a Paula en su propia domesticidad, invade el espacio que prometía ser refugio y cordura: "Eran las llaves de la puerta. El chico las hizo tintinear y se rio y su risa vino acompañada por un eructo sanguinolento. Paula quiso correr, pero, como en las pesadillas, le pesaban las piernas ... Pero no estaba soñando. En los sueños no se siente dolor" (Enríquez, 2016, 153). El final implacable confronta a Paula con la realidad de su propia vida como una pesadilla. El niño caníbal funciona como un espejo confrontando en reversa los horrores de Paula. Ella misma es ese monstruo que había abandonado al niño enfermo en el hogar, ella misma es la mujer monstruo que no puede caber en la domesticidad que Miguel construye para ella. Pero el monstruo funciona aquí 
como una representación de los límites entre realidad y alucinación que Paula no puede distinguir, los límites entre la cordura y la locura, entre la ciudad de la clase media y esta ciudad de adictos y criminales en que ella no puede rescatar a nadie.

El gótico se ha caracterizado con un género del exceso, el exceso en las imágenes, en la construcción de un mundo emocional que parece sobrepasarnos como lectores. Al leer este relato uno puede pensar en otro similar, "La casa de azúcar," de Silvina Ocampo, en donde lo doméstico se vuelve un espacio intolerable e irracional para los protagonistas. Ilse Bussign señala que los relatos góticos construyen una "empatía espacial" en que el espacio ejerce una dominación emocional sobre los protagonistas (Bussign, 2016, 46). Esto es evidente en el relato de Ocampo y en el de Enríquez: se trata de espacios con la capacidad de desestabilizar cualquier intención de domesticidad. La casa embrujada es el arquetipo de estos lugares en que la conexión entre cuerpo y espacio se transforma en una relación de intensa emocionalidad (Bussing, 2016, 57).

En cierto modo, podemos decir que el Gótico se manifiesta como una forma de consumir y ser consumido en un espacio que encarna la heterogeneidad y los contactos culturales. La alternativa parece ser la de consumir o ser consumido tal como ocurre en el relato "Carne" (Enríquez, 2014). En su libro sobre consumo cultural y canibalismo, Deborah Root explora cómo placer y consumo del otro son formas de un canibalismo mediático (Root, 1996, 43-46). El relato de Enríquez se centra en el suicidio de un cantante que había hecho de "la carne" uno de sus slogans favoritos. Espina aparece en una habitación de un hotel muerto después de haberse comido trozos de su cuerpo: "Santiago apareció en una habitación de hotel de Once, con todo el cuerpo cortajeado: había usado una Gillette y un Tramontina a conciencia para despellejarse los brazos, las piernas, el vientre". Luego de su muerte circula una nota escrita con su propia sangre: "Carne es comida. Carne es muerte. Ustedes saben cuál es el futuro" (Enríquez, "Carne", 2014). Son dos admiradoras, Julieta y Mariela, las que finalmente entienden la consigna: "Dos adolescentes habían desenterrado el cajón de Santiago Espina con una pala y sus propias manos. La sepultura, apenas un mes después de su entierro aún no tenía el mármol definitivo que les hubiera dificultado la tarea. Pero la exhumación era apenas un principio. Las chicas habían abierto el féretro para alimentase de los restos del Espina con devoción y asco; alrededor del hueco daban testimonio de su esfuerzo los charcos de vómito" (Enríquez, "Carne, 2014).

La interpretación del cuento puede llevarnos a pensar en la noción del cantante o del ídolo que es "consumido" por su audiencia, pero aquí literalmente. Sin embargo, me gustaría aventurar otra idea: el feminicidio (tal como la pornografía lo hace de manera figurativa) implica un cercenar el cuerpo de la mujer para ser consumido por el victimario, tal como señalaba en la sección anterior. Rita Segato explica la dinámica caníbal que tiene lugar en la violación: "Y aún cuando se disfrace con alguna supuesta finalidad, en última instancia se revela como el surgimiento de una estructura sin sujeto, una estructura en la cual la posibilidad de consumir el ser del otro a través del usufructo de su cuerpo es la caución o el horizonte que, en definitiva, posibilita todo valor o significación" (Segato, 2003, 23).

Esta relación entre violencia de género y canibalismo se revierte en el cuento. Ahora son las niñas-monstruos, aquellas que se deciden a transgredir numerosas barreras, las que llevan a cabo el consumo canibalista del otro. Como en el relato de "Las cosas que perdimos en el fuego", Enríquez nos somete aquí a hacer una examinación crítica de género 
y violencia, al revertir el tropo y mostrar el potencial de lo femenino en la deconstrucción de un orden social. Como señalan Vizcaíno y Ordiz, el caníbal es el monstruo que no puede establecer relaciones sociales con los otros. El caníbal se mueve por el impulso de transgredir el orden de la civilización; la consumición violenta del caníbal lo coloca en el centro de discursos críticos sobre consumo, materialismo y poder" (Casanova Vizcaíno, Ordiz, 2018, 36).

Fred Botting llama a este Gótico contemporáneo el "Gótico postmoderno", un gótico que muestra la obsesión con los cambios sociales y con una modernidad de paradojas, un gótico que revela el horror de la disolución del yo (Botting, 2005, 109). Pero me atrevo a decir que este es un "Gótico caníbal" o más bien, un "Rojo Gótico" en donde la realidad política y social de América Latina muestra los límites y las fricciones que causa el horror de violencias a veces inimaginables. Como hemos visto en las páginas anteriores, no hay alusión, alegoría, o referencia simbólica al terror: el terror se escribe sobre los cuerpos concretos de aquellos y aquellas que sufren las consecuencias de una sociedad global con sus paradojas de acceso mediático y discriminación y violencia neoliberal.

\section{Coda: En piel ajena}

Rebecca Scott Bray analiza la obra de la artista mexicana Teresa Margolles como una escritura sobre la piel ajena, como una mediatización estética de la "vida de la muerte" (Scott Bray, 2007, 15). La trayectoria artística de Margolles se inicia en la morgue, donde recibe formación como forense. Sus primeras obras son parte de un colectivo de artistas SEMEFO, el Servicio Médico Forense, que funda en 1990. El tema recurrente es el de usar materiales médicos forenses (fluidos corporales, piel, ropa de las víctimas o reconstrucciones de escenas de crímenes) como pieza central de una reflexión acerca de la violencia y la falta de justicia y resolución legal. Por ejemplo, en 1997 el grupo exhibe Estudio de la ropa del cadáver, una colección de piezas de ropa que usaron adultos y niños antes de ser asesinados. En esta primera etapa de su obra, Margolles fue muy criticada debido a lo que algunos consideran como una falta de respeto al cadáver, un uso sensacionalista del dolor ajeno. ${ }^{8}$

Sin embargo, sus obras posteriores, individuales, han recibido un considerable elogio de la crítica, por mostrar la realidad de la violencia que tiene lugar en América Latina. ¿De qué otra cosa podríamos hablar? fue la entrada oficial de México para la Bienal de Venecia en 2009. Empleando la sangre que fue recogida de distintas escenas del crimen, Margolles pinta diferentes objetos que simulan una escena de un crimen. Como señala Iván Ramos, la efectividad emocional de esta exhibición reside en el hecho de que se vuelve anónima y colectiva la pérdida de una vida individual (Ramos, 2015, 301). Es en este anonimato que la brutalidad de la violencia que la crítica se potencia, como así también el uso que hace Margolles de un equipo de sonido que durante la instalación repite las voces de los testigos que no hicieron nada. Como en los casos de exhibiciones públicas de fotografías de desaparecidos por la violencia política, la instalación permite un duelo colectivo, un duelo político que demanda la cercanía y el reconocimiento debido a los

\footnotetext{
${ }^{8}$ Ver como ejemplo, el artículo de María Campiglia, quien sostiene que esta forma de "usar" los cadáveres no es sino una reiteración de la muerte. María Campiglia (2014) "Teresa Margolles. Reiterar la violencia" BRAC. Barcelona Research Art Creation. 2.1: 100-125.
} 
materiales orgánicos que se emplean. Como dice Jean Franco, "las víctimas vuelven a espantar a los victimarios" (Franco, 2003, 200, la traducción es mía).

¿Cuál es el peso de las víctimas en esta reedición de un "Rojo Gótico" que sin llegar al género del "Slasher" impone una presencia de una corporalidad monstruosa como un poderoso memento mori en nuestras sociedades? No es casualidad que hayan sido los militares, aquellos que crearon con perversidad la categoría política de "desaparecido": alguien que pervive entre la vida y la muerte. El nuevo "Rojo Gótico" hace de esta desaparición la recurrencia de una pesadilla. Porque, como dice ciertamente Jáuregui el horror tiene un efecto "anticipatorio en la imaginación política" $(2005,880)$. Recuperando a los otros, esta ficción y este arte de extremos sólo puede así, en la materialidad de una piel, de un cuerpo, de unos ojos, escribir otros géneros, otras geografías y otras historias, aquellas que vuelven, que siempre retornan para el espanto.

\section{Bibliografía}

Banerjee, Suparna. 2014. Science, Gender and History: The Fantastic in Mary Shelley and Margaret Atwood. Newcastle Upon Tyne: Cambridge Scholars Publishing.

Barrancos, Dora y Mariana Carbajal. 2020. "Dora Barrancos: La historia de los feminismos es una reivindicación de derechos. Página 12. 30 de noviembre de 2020. https://www.pagina12.com.ar/308851-dora-barrancos-la-historia-de-los-feminismoses-la-historia-

Botting, Fred. Gothic. 2005. London and New York: Routledge.

Braidotti, Rosi. Lo Posthumano. 2015. Traducción de Juan Carlos Gentile Vitale. Barcelona: Geidisa.

Bussing, Ilse. 2016. "Complicit Bodies. Excessive Sensibilities and Haunted Space." Horror Studies 7.1: 41-59.

Cabezón Cámara, Gabriela. Iñaki Echeverría. 2013. Beya. (Le viste la cara a Dios). Buenos Aires: Eterna Cadencia.

Cabezón Cámara, Gabriela y Nora Domínguez. 2014. "Conversaciones y reenvíos con Gabriela Cabezón Cámara. Cuadernos Lírico. 10: 1-6.

María Campiglia (2014) "Teresa Margolles. Reiterar la violencia" BRAC. Barcelona Research Art Creation. 2.1: 100-125. 
Casanova-Vizcaíno, Sandra e Inés Ordiz. 2018. Latin American Gothic in Literature and Culture. New York: Routledge.

Casas, Ana. 2012. "Las mil caras del monstruo". Las mil caras del monstruo. Sevilla, España: Bracket Cultura, 5-15

Eljaik-Rodríguez, Gabriel. 2018. The Migration and Politics of Monsters in Latin American Cinema, Palgrave McMillan.

Eljaik-Rodríguez, Gabriel 2017. Selva de Fantasmas: El gótico en la literatura y el cine latinoamericanos. Colombia: Universidad Javeriana.

Enríquez, Mariana. 2014. "Carne". Página 12. Viernes 24 de enero de 2014. https://www.pagina12.com.ar/diario/verano12/subnotas/23-66588-2014-01-24.html

Enríquez, Mariana. 2014. La hermana menor. Un retrato de Silvina Ocampo. Barcelona: Editorial Anagrama.

Enríquez, Mariana. 2016. Las cosas que perdimos en el fuego. Barcelona: Anagrama.

Escoda Agusti, Clara. 2007. "I Carve Myself into My Hands" The Body Experienced from Within Ana Mendieta's Work and Migdalia Cruz's Miriam's Flowers. Hispanic Review, Summer, 289-311.

Franco, Jean. 2003. Cruel Modernity. Durham, NC: Duke University Press.

Gonzáles Rodríguez, Sergio. (2005). Huesos en el desierto. Tercera Edición. Barcelona: Anagrama.

Hall, Harriet. 2018. "Who was Mary Shelley and What Inspired Frankenstein?" The Independent, September 17, 2018. https://www.independent.co.uk/lifestyle/women/mary-shelley-movie-frankenstein-books-husband-trailer-biographyquotes-a8433531.html

Haraway, Donna. 2005. The Haraway Reader. New York and London: Routledge.

Jackson, Rosemary. Fantasy: The Literature of Subversion. Methuen, New York, 1981.

Klingenberg, Patricia N., and Fernanda Zullo-Ortiz, eds. 2016. New Readings of Silvina Ocampo. Beyond Fantasy. Woodbridge: Tamesis.

Jáuregui, Carlos. 2005. Canibalia. Canibalismo, calibanismo, antropofagia cultural y consumo en América Latina. Habana, Cuba: Casa de las Américas.

Kilgour,Maggie. 1990. From Communion to Cannibalism: An Anatomy of Metaphors of Incorporation. Princeton: Princeton University Press. 
Mannoni, Octave. 1993. Prospero and Caliban. The Psychology of Colonization. New York: Praeger.

Mulvey-Roberts, Marie. 2016. Dangerous Bodies: Historicising the Gothic Corporeal. Manchester: Manchester University Press.

Olmedo, Nadina Estefania. 2010. "Ecos Góticos en la novela y el cine del cono Sur." $\mathrm{PhD}$ dissertation. University of Kentucky.

Ramos, Iván. 2015. "The Viscosity of Grief: Teresa Margolles at the Scene of the Crime". Women and Performance: A Journal of Feminist Theory. 25.3: 298-314.

Root, Deborah. 1996. Cannibal Culture: Art, Appropriation and the Commodification of Difference. London, New York: Routledge.

Scott Bray, Rebecca. 2007. "En Piel Ajena: The Work of Teresa Margolles." Law Text Culture 11: 13-50.

Segato, Rita Laura. 2010. "Territory, Sovereignty, and Crimes of the Second State," translated by Sara Koopman. In Terrorizing Women: Feminicides in the Américas, edited by Rosa-Linda Fregoso and Cynthia Bejarano, 70-92. Durham, NC: Duke University Press.

Segato, Rita Laura. 2003. Las estructuras elementales de la violencia. Ensayos sobre el género entre la antropología, el sicoanálisis y los derechos humanos. Quilmes: Prometeo.

Selnes, Gisle. 2008. "The Femenine (Ob)scene of Cruelty. On the Fantastic, Its Genealogy and Margins". Orbis Litterarum: 511-528.

Serrano, Carmen. 2009. "Monsters, Vampires and Doppelgängers: Innovation and Transformation of Gothic Forms in Latin American Narratives." PhD Dissertation, University of California at Irvine.

Soltysik Monnet, Agnieszka. 2016. "Gothic Matters: Introduction." Text Matters. A Journal of Literature, Theory and Culture. 6: 7-14. 